\title{
Effect of valerian capsule on anxiety and quality of life in type 1 diabetes: a clinical trial
}

\author{
Salehi $S^{1}$, Valiee $S^{2}$, Ghafoori $S^{3}$, Roshani $D^{4}$, Fathi $M^{5}$ \\ 1. MSc Student of Medical-Surgical Nursing, Student Research Committee, Kurdistan University of Medical Sciences, Sanandaj, \\ Iran. ORCID ID: 0000-0001-9789-6672 \\ 2. Associate Professor of Nursing, Clinical Care Research Center, Research Institute for Health Development, Kurdistan \\ University of Medical Sciences, Sanandaj, Iran. \\ 3. Assistant Professor of Adult Glands and Metabolism, Liver and Digestive Research Center, Research Institute for Health \\ Development, Kurdistan University of Medical Sciences, Sanandaj, Iran. \\ 4. Associate Professor, Social Determinants of Health Research Center, Research Institute for Health Development, Kurdistan \\ University of Medical Sciences, Sanandaj, Iran. \\ 5. Assistant Professor of Nursing, Clinical Care Research Center, Research Institute for Health Development, Kurdistan \\ University of Medical Sciences, Sanandaj, Iran (Corresponding Author), Tel: +98-8733627636, Email: \\ mohammad.fathi@muk.ac.ir, ORCID ID: 0000-0001-9624-4760
}

\begin{abstract}
Background and Aim: Treatment and complications of type 1 diabetes can affect the mental status of patients and their quality of life. The aim of this study was to determine the effect of valerian capsule on anxiety and quality of life in the patients with type 1 diabetes.

Material and Method: This study was a clinical trial and included 82 patients with type 1 diabetes (control group 40 and intervention group 42). Intervention group received one capsule of Sedamin (containing $530 \mathrm{mg}$ of valerian root extract) every night one hour before bed time, for eight weeks. Control group received a placebo capsule. Beck Anxiety Inventory was completed before the study and also after the $4^{\text {th }}$ and $8^{\text {th }}$ weeks of the study, and quality of life questionnaire (DQOL) was completed before and eight weeks after the study. Using SPSS 24 software, data were analyzed by independent t-test, paired samples t-test and one-way covariance with repeated measures.

Results: The results showed that there was no significant difference in the anxiety scores between the two groups before the intervention and after four weeks of study. But we found a significant difference between the groups after eight weeks of study $(p=0.008)$. After the intervention, the quality of life scores in the intervention and control groups were $4.05 \pm 0.7$ and $3.23 \pm 0.43$ respectively indicating a significant difference between the two groups $(p=0.0001)$.

Conclusion: The findings showed that use of valerian capsules for eight weeks reduced the anxiety in the patients with type 1 diabetes and improved their quality of life. We recommend use of this herbal medicine in the patients with type 1 diabetes and anxiety.
\end{abstract}

Keywords: Diabetes, Anxiety, Quality of life, Valerian

Received: Jan7, 2019

Accepted: April 17, 2019

How to cite the article: Salehi S, Valiee S, Ghafoori S, Roshani D, Fathi M. Effect of valerian capsule on anxiety and quality of life in type 1 diabetes: a clinical trial. SJKU 2019;24(3):55-66. 


\title{
تاثير كيسول خوراكى سنبل الطيب بر اضطراب و كيفيت زندىى بيماران مبتلا به ديابت نوع يك: يك كار آزمائى بالينى
}

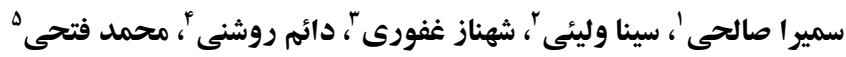

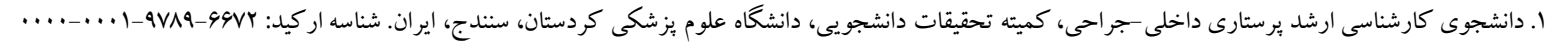

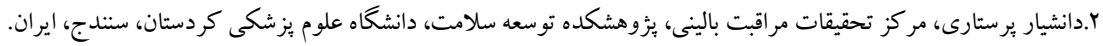

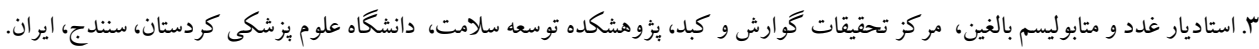

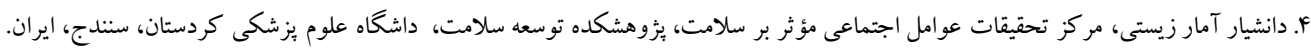

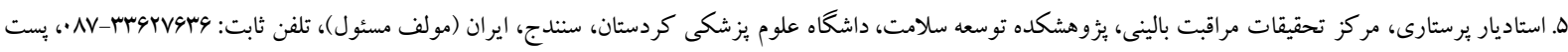

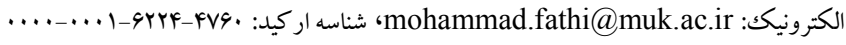

جـكيده

زمينه و هدف: ديابت نوع يكى، درمان و عوارض آن مى تو اند وضعيت روانى مبتلايان و كيفيت زندگى آنان را تحت تاثير قرار دهد.

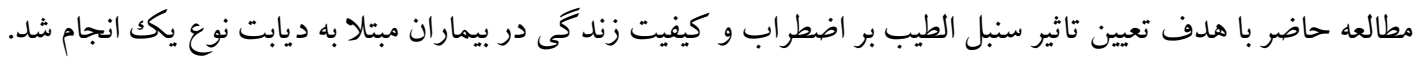

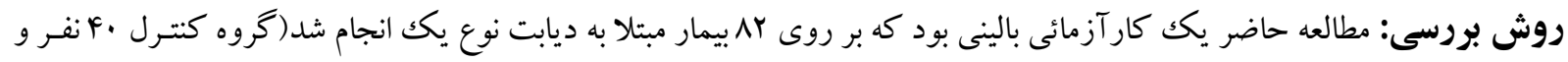

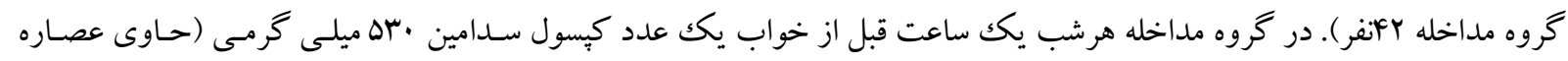

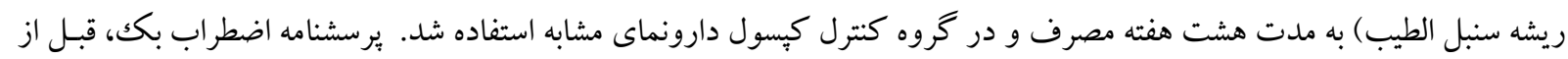

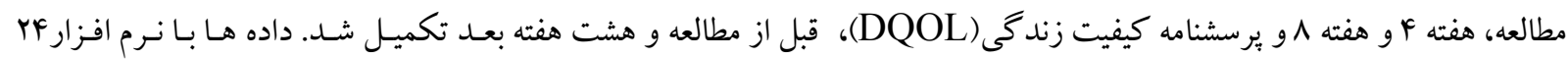
و و آزمون هاى آمارى TPSS

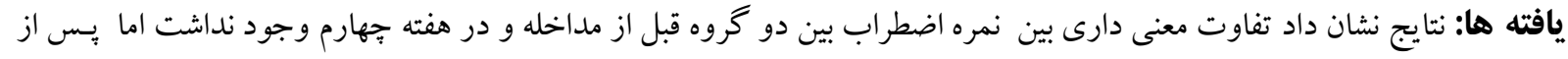

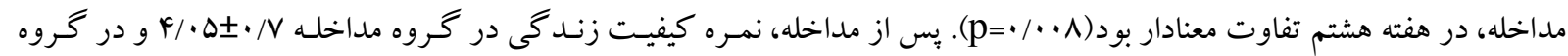

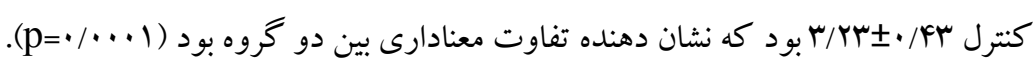

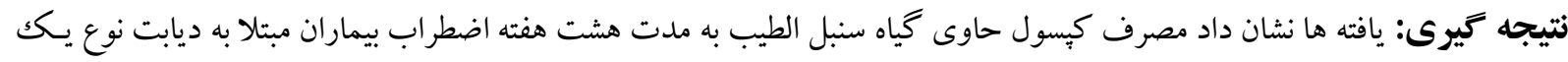

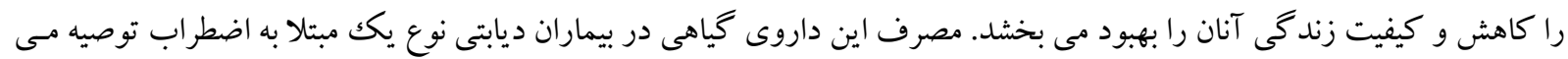




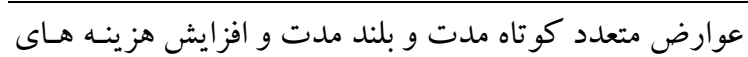

$$
\text { درمانى مى گردند (·) (1). }
$$

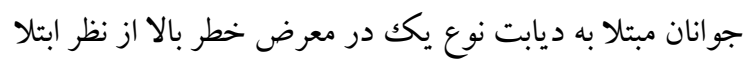

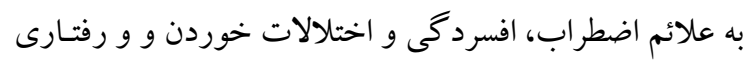

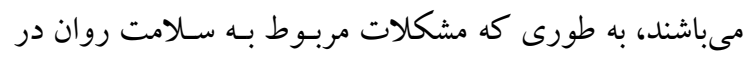

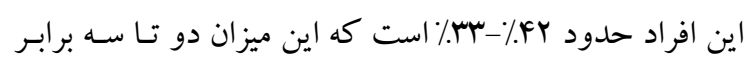

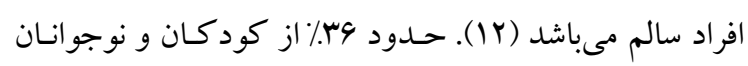

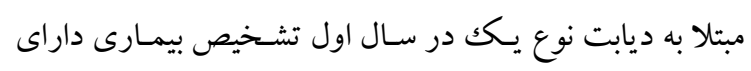

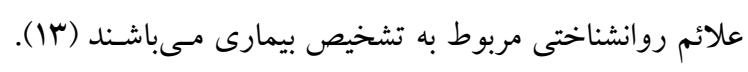

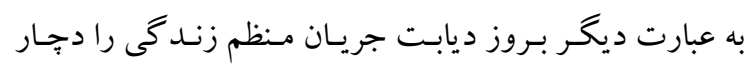

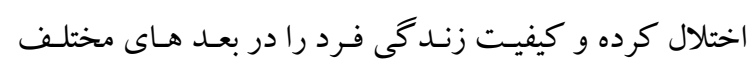

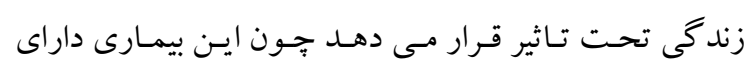

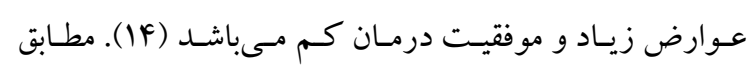

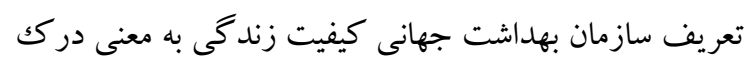

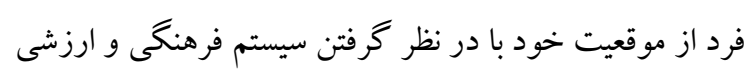

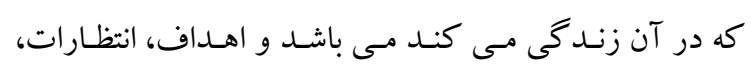

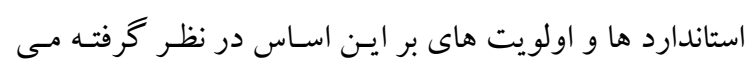

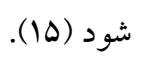

مديريت ديابت نوع يكك بيجيجيده بـوده و بـه تغييـرات مهـم در

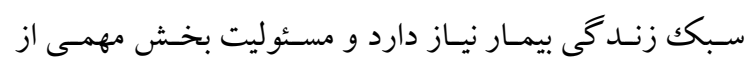

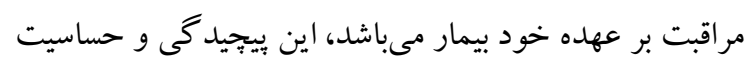

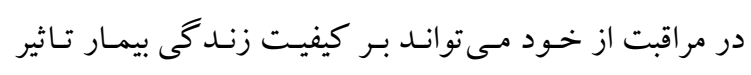

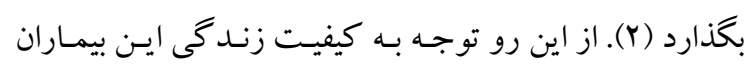

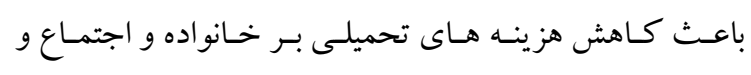

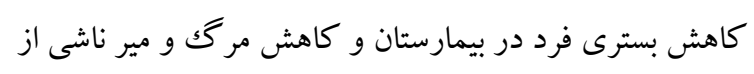

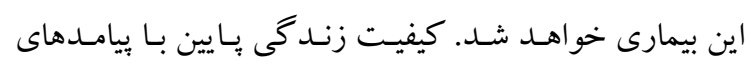

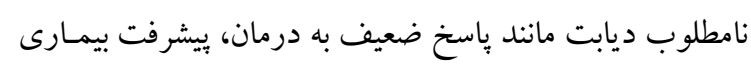

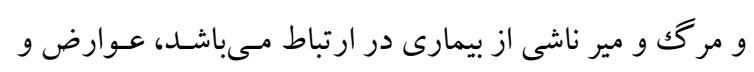

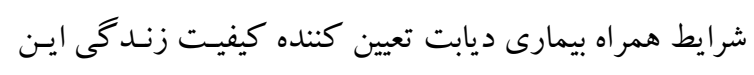

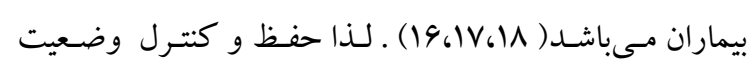

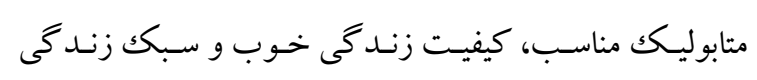

مقدمه ديابـت يكى از شـايع تـرين بيمـارى مـزمن متابوليكك دوران

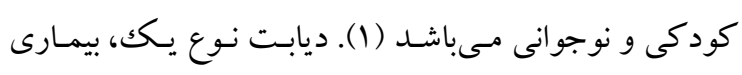

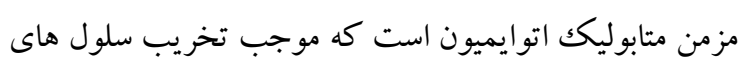

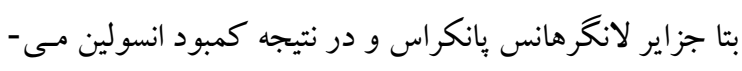

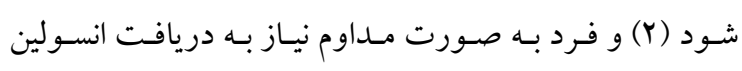

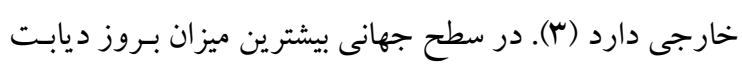

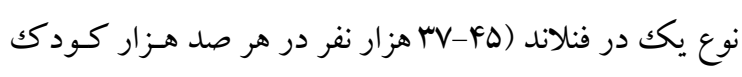

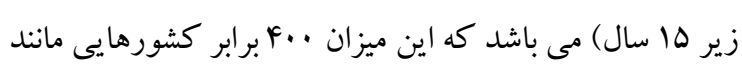

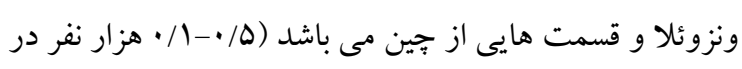

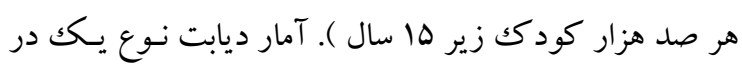

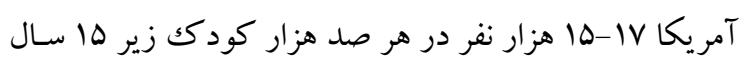

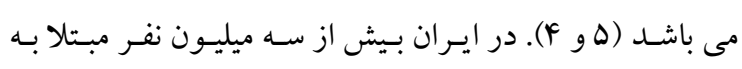

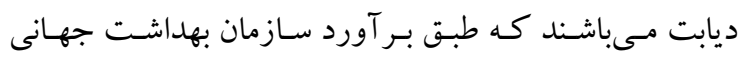

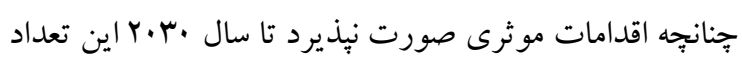

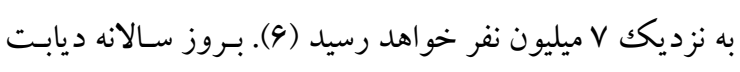

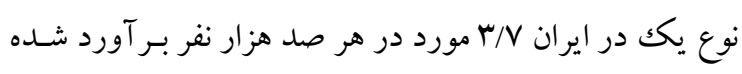

(V) (V) (V) ديابت و عـوارض ناشسى از آن بـر عملكـرد جسمى، وضسعيت

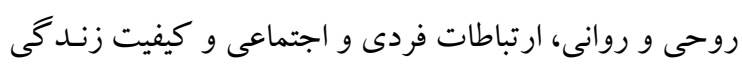
فرد تاثير مى گذارد (^). از طرفى نوجوانى دوره ایى از تغييرات

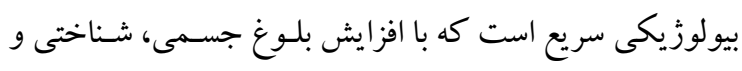

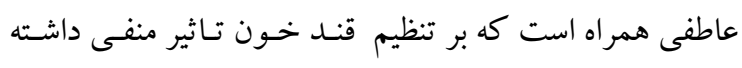

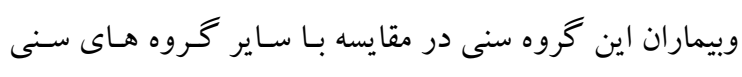

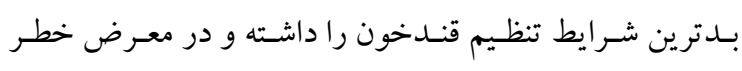

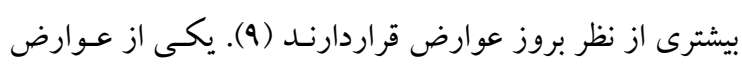

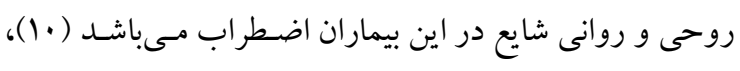

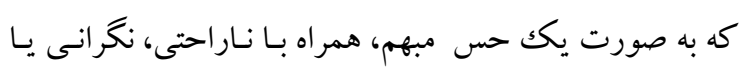

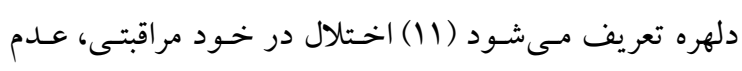

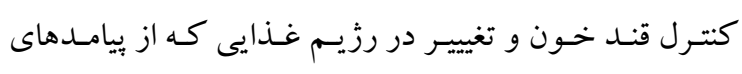

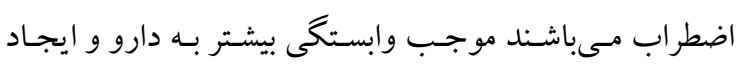


... تاثير كيسول فوراكَ

جهت كاهش مشكلات روانشناختى و جسمى كـه در كـاهش

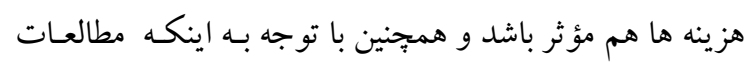

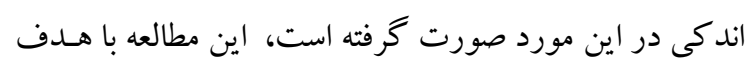

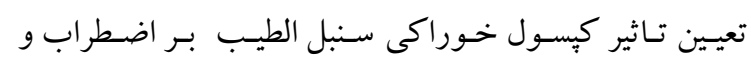

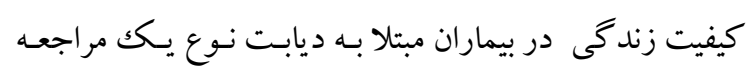
كننده به بيمارستان توحيد سنندج در سال و I ا انجام شد.

\section{روش بروسى نوع مطالعه}

اين مطالعه يكك كار آزمايى بالينى نيمه تجربى دو سو كور بـود

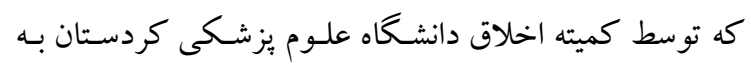

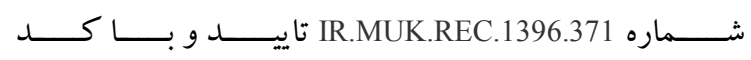
در سامانه ثبت كار آزمايى بـالينى و بــ IRCT20181126041754N1

ثبت شد.

نمونه كيرى

يس از كسب مجوزهاى لازم به نفر از بيماران مبتلا به ديابـت

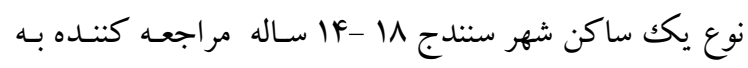
درمانگاه ديابت بيمارستان توحيد و انجمن دايره آبى سـنندج در سال VY I ا به روش هدفمند انتخاب و به روش تصـادفى بـه يكى از گروه هاى مداخله يا كنترل تخصيص داده شـدند (هـر

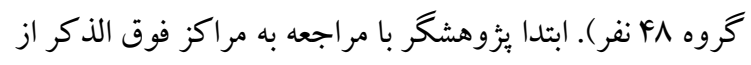

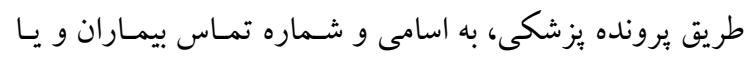

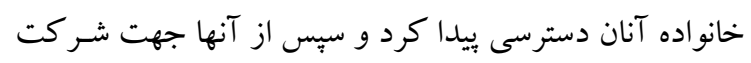
در كلاس درس كلينيك ديابت توحيد دعوت بـه عمـل آورد.

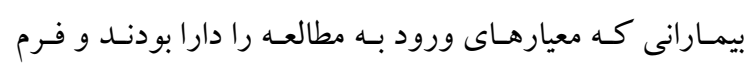
رضايت آكاهانه را تكميل و امضـا نمـوده بودنـد، وارد مطالعـه شدند (فلو جارت شماره يكك). معيارهاى ورود به مطالعه شامل كذشتن حداقل يكك سال از تشخيص ديابـت نـوع يـك، عـدم سابقه ابتلا به بيمارى روحى و روانى، عدم استفاده از هر گونـه داروى مسكن و خواب آور، عدم سـابقه حساسـيت بـه داروى

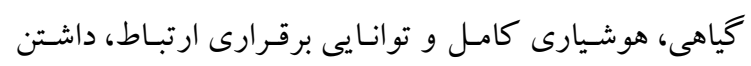

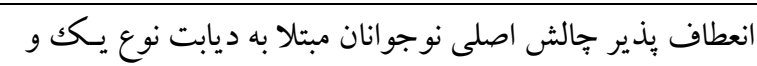

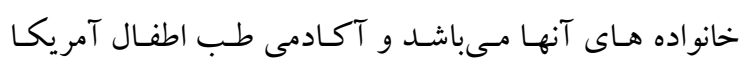
كزارش كرده است كه صرفا مديريت بزشكى ديابت نوع يك اده كافى نيست بلكه كيفيت زندگى مرتبط با سـلامت كودكـان و افزايش ظرفيت سـاز كارى و توسـعه بيشـرفت بـه سـوى دوران بزر گسالى سالم نيز بايد مورد توجه قرار گيـرد (rا). بنسابر ايسن اضطراب و كيفيت زندگى نوجوانان نيازمند مداخله است.

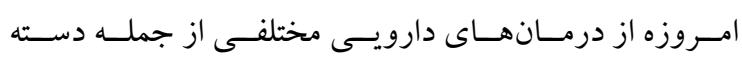
بنزوديازيين ها جهت كاهش اضطراب بيماران استفاده مىشود (19). طبق آمار سازمان بهداشت جهانى، در بيشـتر كشـورهاى صنعتى، • V تا هو درصد از مردم از طـب سـنتى از جملـه كيـاه

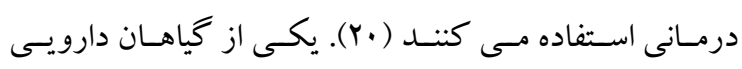
يرمصرف، سنبل الطيب است كه به علف گربه نيز معروف مسى

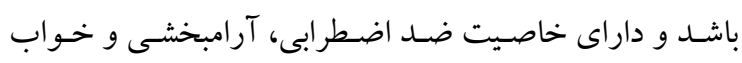
آورى مى باشد ( (Y). مطالعات نشان داده اند كـه سـنبل الطيـب داروى بـى خطرى اسـت و از نظر بـالينى در درمـان اضطراب ايمن و اثـربخش اسـت امـا ايمـن بـودن مصـرف آن در دوران باردارى و شـيردهى فعـلا ثابـت نشـده اسـت و بايسـ طبـق نظـر

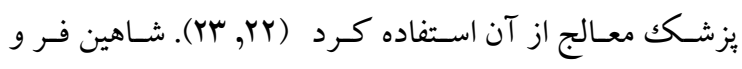

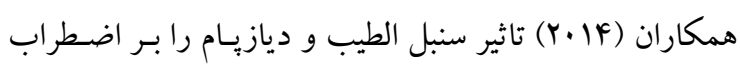
قبل از عمل جراحى مقايسه كردند. دريافنتد كـه سـنبل الطيـب همانند ديازيام اضطراب را به مقدار قابل توجهى كـاهش داد و و به دليل عوارض كمتر نسبت بـه ديازيـام مسى توانس جـايكزين

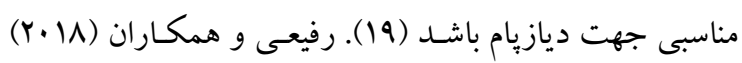

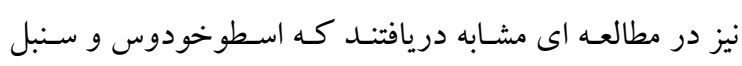

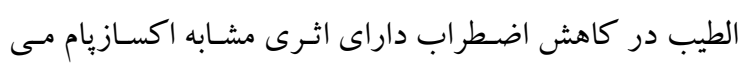

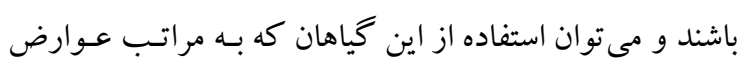

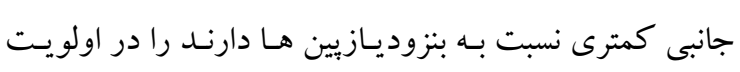

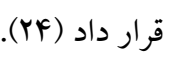
با توجه بـه شـيوع بـالاى ديابـت و تـاثير آن بـر روح و روان و

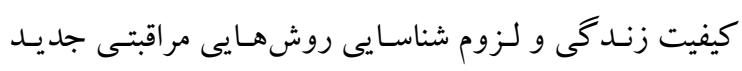




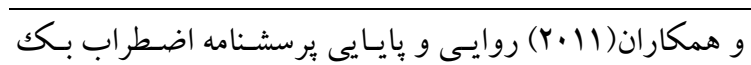

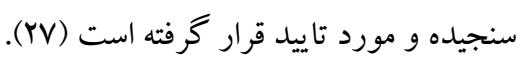

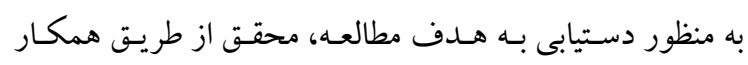

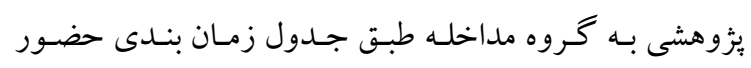

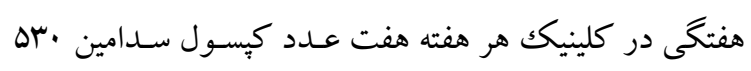

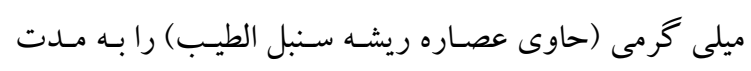

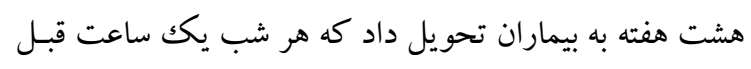

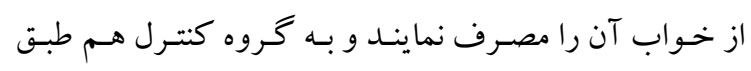
جدول زمان بندى حضور هفتخى هر هفته هفت عـدد كيسول

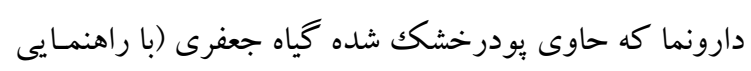

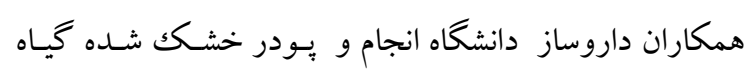
جعفرى در داخل كيسولهاى شفاف كاملا مشابه سدامين بـوده و از نظر شكل، ظاهر و رنكُ هيج گونه تفاوتى با هم نداشتند

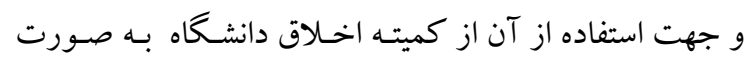

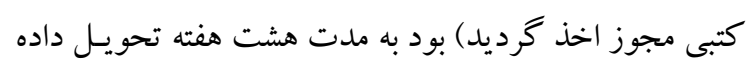

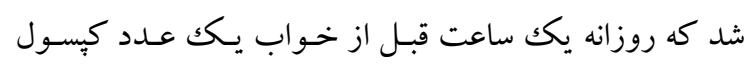
دارونما را مصرف نمايند. همكار يُزوهشى و بيماران تـا بايسان

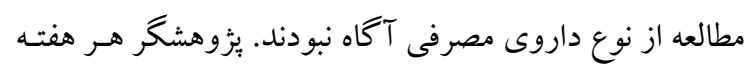

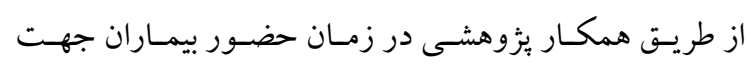

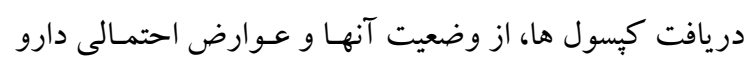

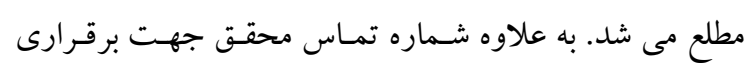

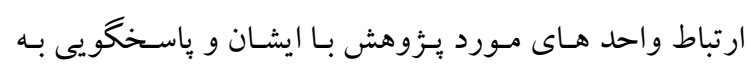

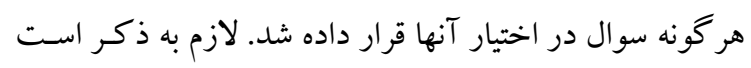

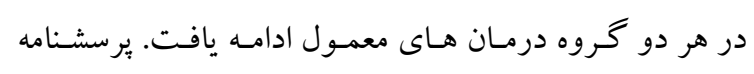

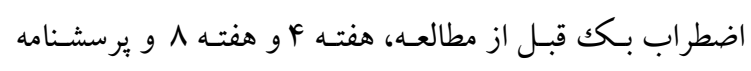

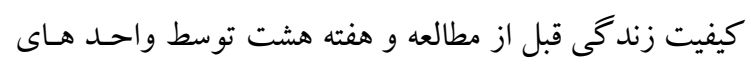

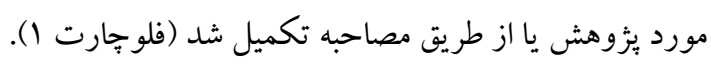
ملاحظـات اخلاقى از جملـه كسـب مجـوز اخـلاق از كميتـه

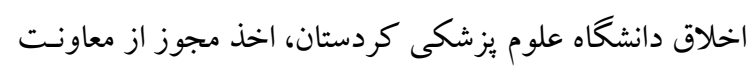

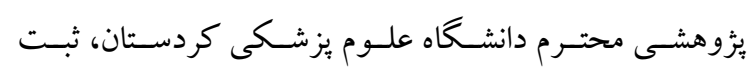

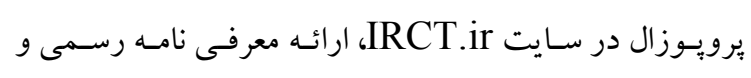

سواد خواندن و نوشتن، عدم ابتلا به بيماريهاى كبـد و كليه و

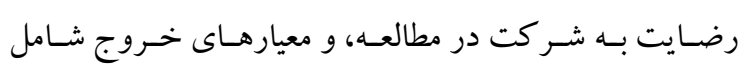

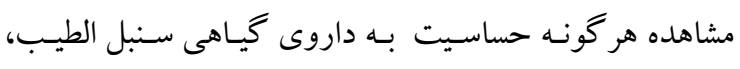

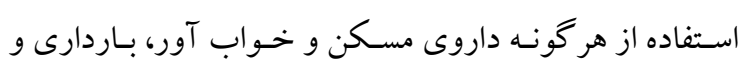

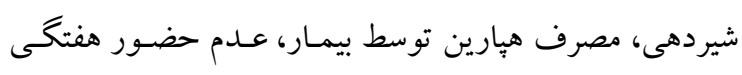

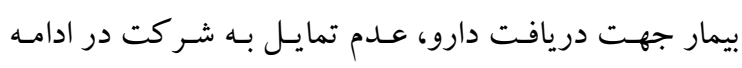
مطالعه در هر مرحله و بسترى شدن در بيمارستان در حين انجام مطالعه بود.

\section{روش مداخله و ابزار كردآورى اطلاعات}

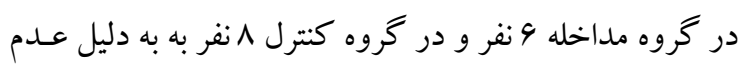

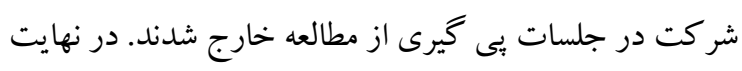

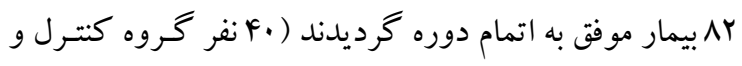

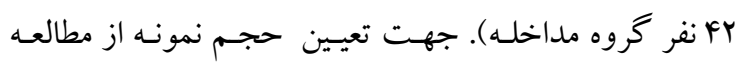

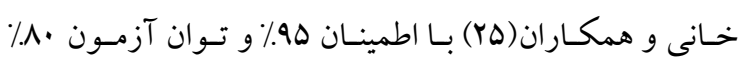

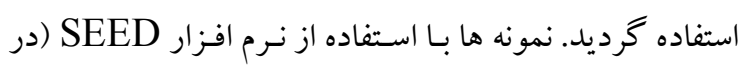

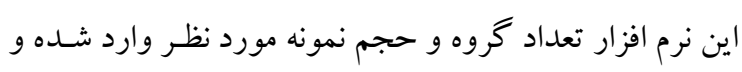

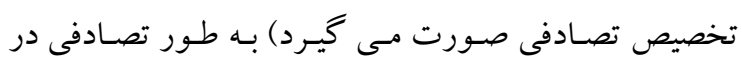

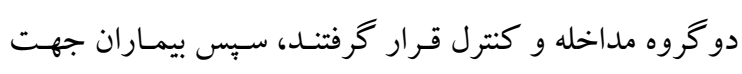

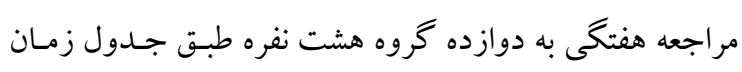

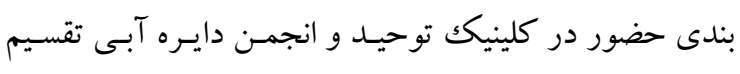

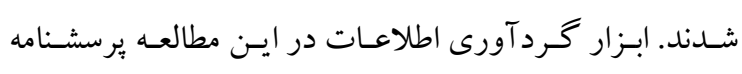

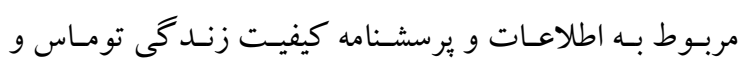
Diabetes quality-of-life (DQOL) همكــاران و و يرسشـنامه اضطراب بـكك بـود. ايسن ابزارهـا بـه

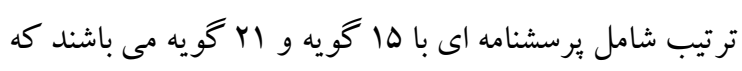

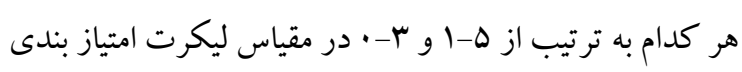

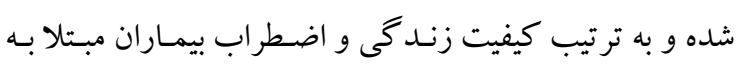

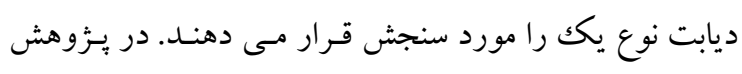

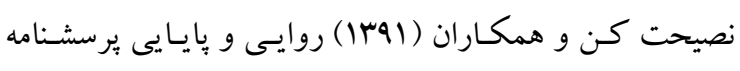

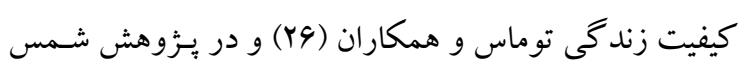


4... كاثير كيسول فوراكى

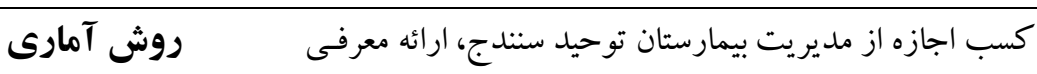

جهت تجزيه و تحليل داده هاى يـزوهش از نـرم افزار نامه رسمى به مسؤل محترم كلينيكك تخصصى، توضيح هـدف ورزن YF و روش هاى آمار توصيفى از جمله توزيع فراوانى و

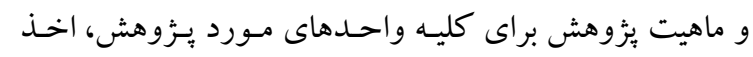
شاخص هاى مركزى (مانند محاسبه ميانگين و انحراف معيار)،

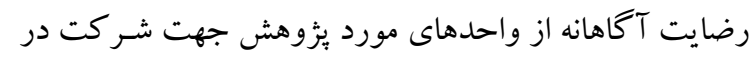

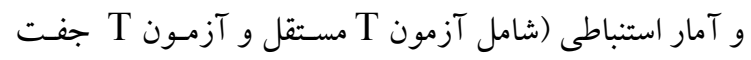

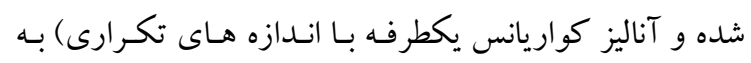

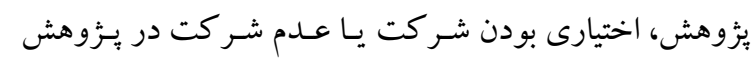
براى كليه واحدهاى مورد برزوهش، اطمينان از محرمانسه بـودن

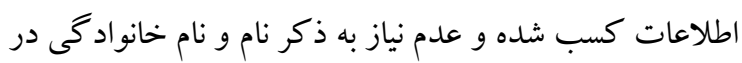

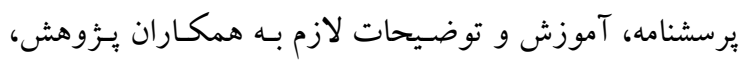

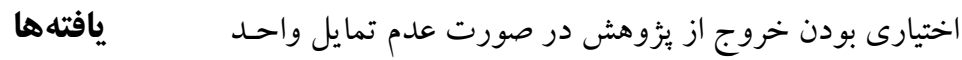
يافته هاى مطالعه نشان داد •ه درصد واحدهاى مورد يـزّوهش هاى مورد يُزوهش به ادامه شركت در يُزوهش، اطمينـان دادن

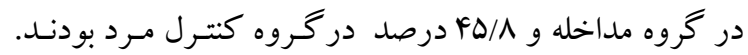
به واحدهاى مورد يزٔوهش كـه در صسورت خـروج از مطالعه

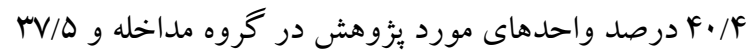
درصـد در گـروه كنتـرل در اقـوام آنهـا سـابقه ديابـت وجـود هيجِگ نه خللى در ادامه درمان و مراقبت آنان صورت نخواهد

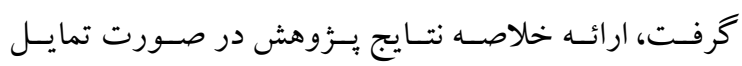
داشت. مشخصات دو گروه قبل از مداخله يكسان بود (جـدول واحدهاى مورد يـرّوهش و مســؤين محتـرم در ايـن يـرّوهش

رعايت شد.

فلو جارت ا: تخصيص نمونه ها در گروه مداخله و كنترل

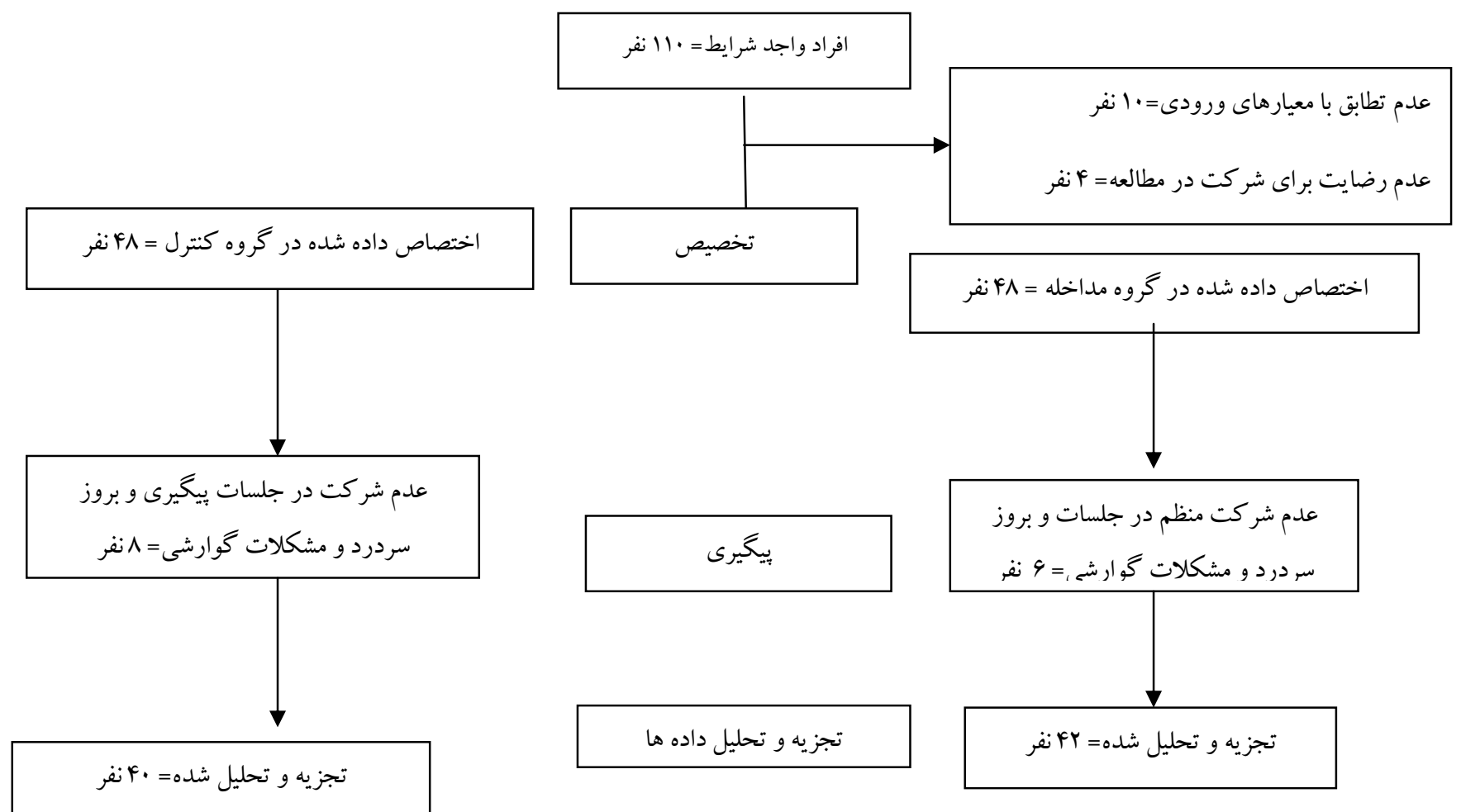

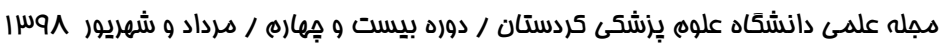




\begin{tabular}{|c|c|c|c|c|c|c|}
\hline \multirow[t]{2}{*}{ p-value } & \multicolumn{3}{|c|}{ كنترل } & \multirow{2}{*}{ تعداد } & & \multirow[b]{2}{*}{ متغير } \\
\hline & درصد & تعداد & درصد & & & \\
\hline \multirow[b]{2}{*}{$\mathrm{p}=\cdot / 9 \wedge \mu$} & $F \Delta / \Lambda$ & rr & $\Delta$. & YF & مرد & \multirow{2}{*}{ جنس } \\
\hline & $\Delta F / Y$ & re & $\Delta$. & YF & زن & \\
\hline $\mathrm{p}=\cdot \mid \wedge \mu^{\prime}$ & $\Delta \cdot$ & FA & $\Delta$. & FA & $\mid f-11$ & سن \\
\hline \multirow{2}{*}{$\mathrm{p}=\cdot / \mathrm{Y} / \mathrm{V}$} & $\Lambda \mu / \mu$ & f. & $91 / V$ & FF & مجرد & \multirow[b]{2}{*}{ وضعيت تاهل } \\
\hline & $19 / \mathrm{V}$ & $\wedge$ & $\Lambda / \mu$ & F & متاهل & \\
\hline \multirow{3}{*}{ p=. } & $9 / \pi$ & $r$ & $\Lambda / r$ & f & ابتدايى & \multirow{3}{*}{ مقطع تحصيلى } \\
\hline & $\mathrm{Fr} / \mathrm{\Lambda}$ & rI & $r Q / r$ & If & راهنمايى & \\
\hline & $\Delta \cdot$ & YF & $9 Y / 0$ & $r$. & متوسطه & \\
\hline \multirow{3}{*}{$\mathrm{p}=\cdot / r Y \mu$} & $14 / 9$ & V & $19 / \mathrm{V}$ & $\wedge$ & بيكار & \multirow{3}{*}{ شغل } \\
\hline & $r Q / r$ & if & $1 F / 9$ & V & آزاد & \\
\hline & $\Delta 9 / \mu$ & TV & $9 N / 1$ & r & محصل & \\
\hline \multirow{2}{*}{$\mathrm{p}=\cdot / 11 \mathrm{~V}$} & $\Lambda \mathrm{V} / \Delta$ & Fr & $V \Delta$ & re & بله & \multirow[t]{2}{*}{ ييمه } \\
\hline & $1 Y / \Delta$ & 9 & ro & Ir & خير & \\
\hline \multirow[b]{2}{*}{$\mathrm{p}=\cdot / \mathrm{V} /$} & $r V / \Delta$ & 11 & $F \cdot / f$ & 19 & بله & \multirow[b]{2}{*}{ ديابت اقوام } \\
\hline & $9 Y / 0$ & $r$. & $\Delta Q / 9$ & r^ & خير & \\
\hline \multirow{3}{*}{$\mathrm{p}=\cdot / \cdot 1 \mathrm{r}$} & r & 19 & $r \Delta / \mathcal{F}$ & IV & ضعيف & \multirow{3}{*}{ سطح در آمد } \\
\hline & $9 Y / 0$ & $r$. & $9 Y / \Delta$ & $r$. & متوسط & \\
\hline & $r / r$ & r & $r / l$ & 1 & بالا & \\
\hline \multirow{3}{*}{$\mathrm{p}=\cdot / r V r$} & $r / 1$ & 1 & $9 / 0$ & $r$ & بيكار & \multirow{3}{*}{ شغل بدر } \\
\hline & $99 / \mathrm{V}$ & rr & VI/V & r & آزاد & \\
\hline & $\mu 1 / \mu$ & 10 & $r \mid / V$ & 1. & كارمند & \\
\hline \multirow{3}{*}{$\mathrm{p}=\cdot / \mathrm{V} \mid \mathrm{r}$} & $\Lambda 1 / r$ & rq & $\Lambda V / r$ & FI & خانه دار & \multirow{3}{*}{ شغل مادر } \\
\hline & $F / r$ & r & $r / 1$ & 1 & آزاد & \\
\hline & $14 / 9$ & V & $1 \cdot 19$ & $\Delta$ & كارمند & \\
\hline
\end{tabular}

بين دو گروه از نظر اين متغير تفاوت معنـادارى وجـود داشـت $\cdot(\mathrm{p}=\cdot / \cdot \cdot \wedge)$

همانطوركـه در جـدول Y مشـخص اسـت درگــروه مداخلـه، تفاوت معنادارى بين نمره اضطراب قبل و بعد از مداخله وجود

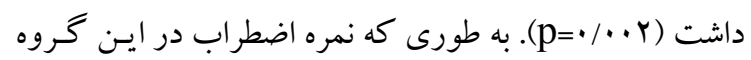

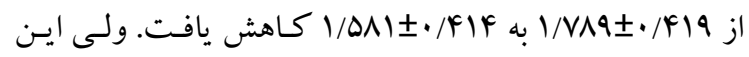
تفاوت در گرووه كنترل معنى دار نبود .
يافته هاى مطالعه نشان داد ميانگين اضطراب در گروه مداخلـه قبل از مداخله بوده است. نتـايج آزمـون تـى مسـتقل نشـان داد تفـاوت معنسى

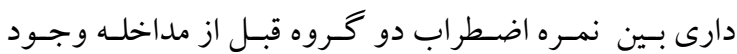

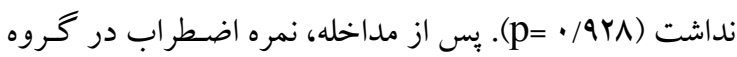

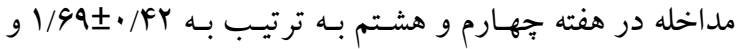

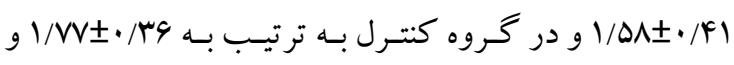

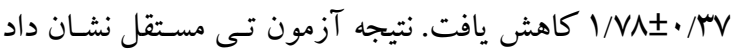




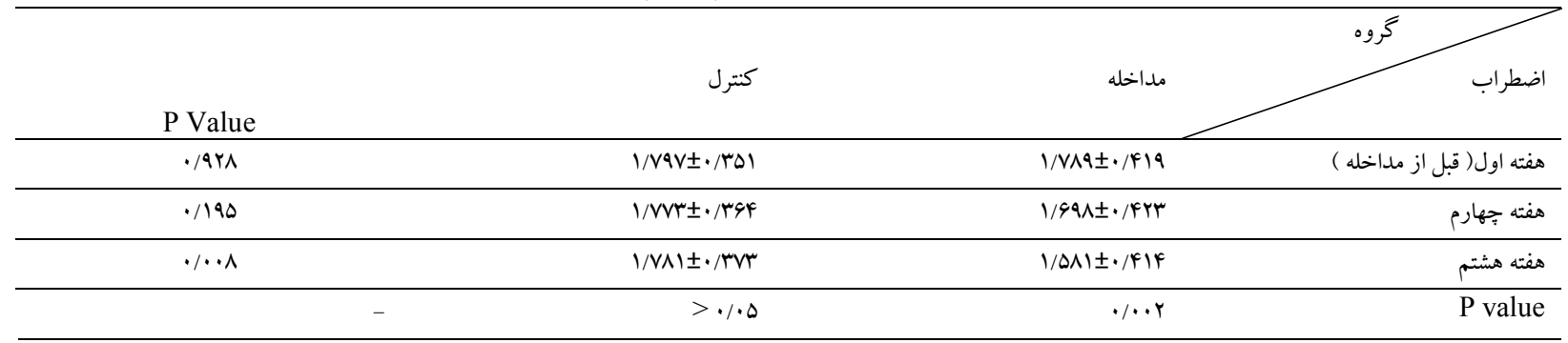

بين دو گروه از نظر ايـن متغيـر تفـاوت معنـادارى وجـود دارد

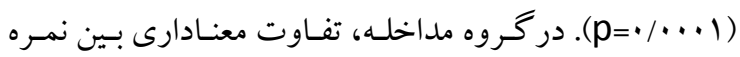

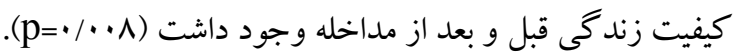
به طورى كه نمره كيفيت زندگى در اين گروه از

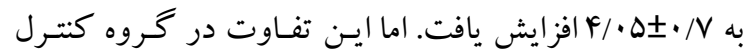
$(\mathrm{p}=\cdot / \uparrow \wedge \vee)$ دار نبب P Value

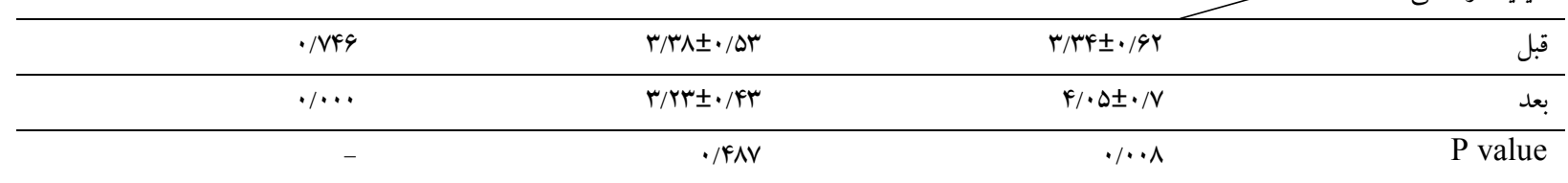

نمودار ا تغييرات ميزان اضطراب در دو گُروه مداخله و كنترل قبل و بعد از مداخله را در زمان هاى مختلف اندازه گيرى نشان مى دهد.

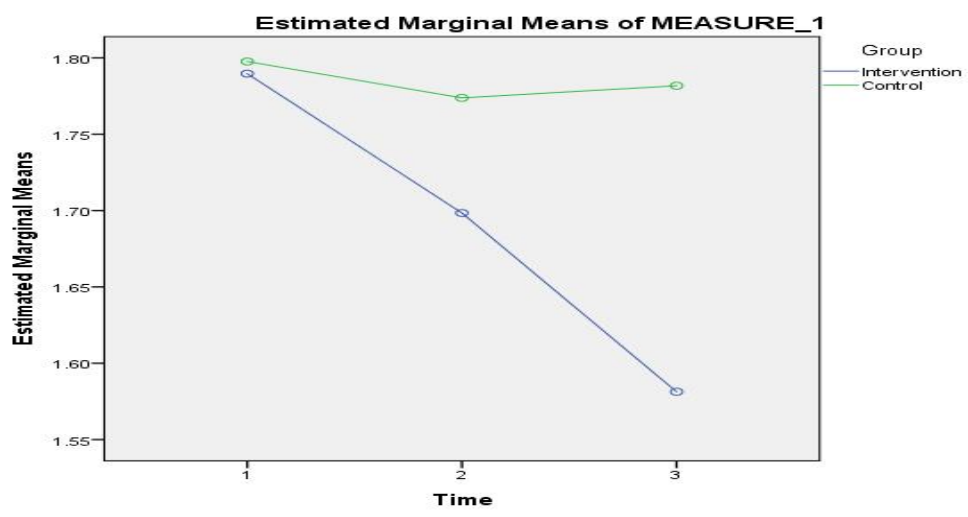

نمودار ا : تغييرات ميزان اضطراب در دو گروهه مداخله و كنترل قبل و بعد از مداخله 
است كه سنبل الطيب بر كاهش اضطراب بيماران تاثير مثبت داشته و با كاهش اضطراب رضايتمندى بيشترى حاصل شده و

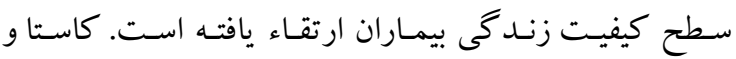

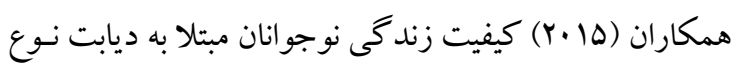
يكك را مورد ارزيابى قرار دادند و نشان دادند بين در آمد بِايين خانواده، جنسيت، كمك هاى بهداشت عمومى و نوع انسولين دريافتى و مدت زمان ابتلا به ديابت، با ميزان رضايت و كيفيت

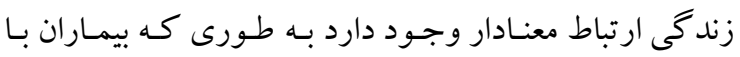

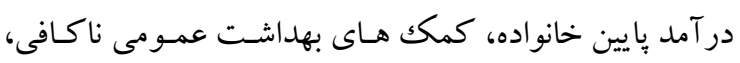
حضـور در مــارس عمـومى، جــس مونــث، سـطح بــايين تحصيلات والدين و مدت زمان طولانى تر ابتلا بـه ديابـت در كل داراى نمره كيفيت زندگى يايين ترى بودند (YF). مايـا و همكاران (r| •r) اضطر اب و افسردگى بيماران مبتلا به ديابت

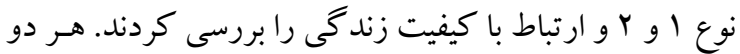

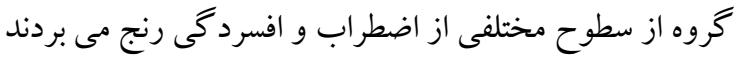

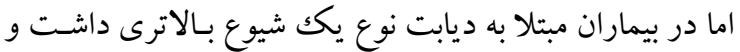

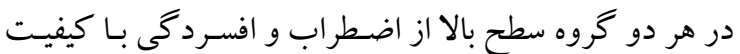

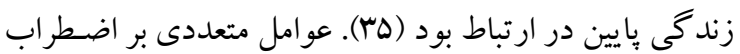

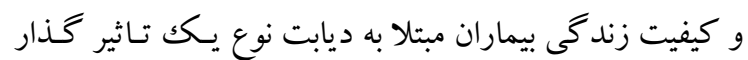

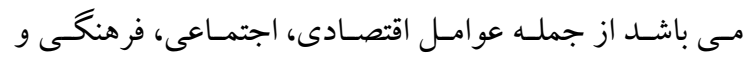

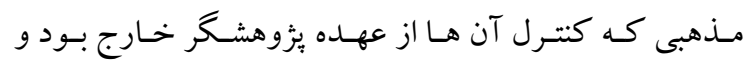
همجِنين مطالعه حاضر در محدوده سنى مشـصص كـه احتمـال

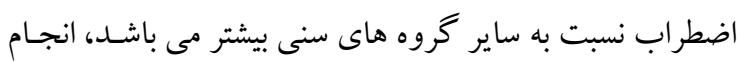

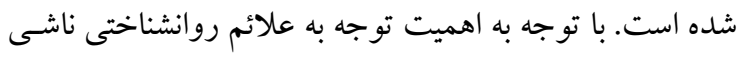
از بيماريهاى مزمن در كنار علائم جسـمى، ييشـنهاد مى شـود بهـ

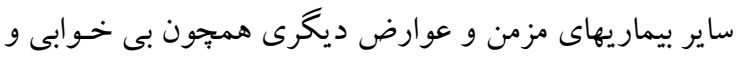

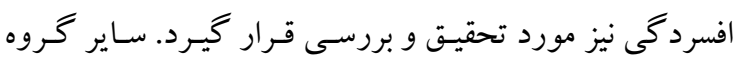

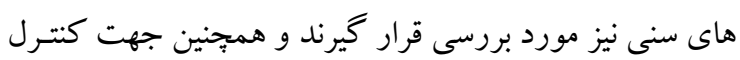
عوارض روحى و روانى ناشى از بيماريهاى مـزمن استفاده از

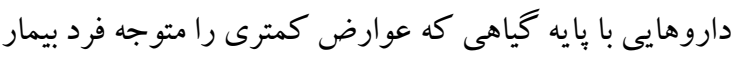
مى نمايد ارجحيت داشته باشد. يافته هاى اين يُزوهش نشـان داد كـه كِيسول خـوراكى سـبل

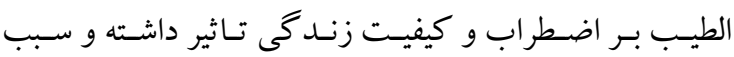

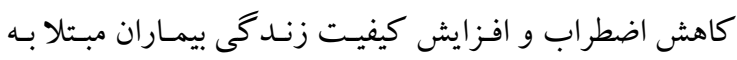
ديابت نوع يكك شده است. شاهين فر و همكاران (هوبا ) نشان دادند عصاره ريشه سنبل الطيب باعث كاهش اضطر اب بيماران قبل از عمل جراحى مى شود كه مطالعه حاضر با آن همخوانى دارد (11). نتايج مطالعه غريب و همكاران (1) (Y) نشان دمان دهنده

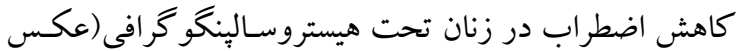
بردارى از رحم و لوله هاى فالوٍ) بعد از مصرف سنبل الطيب

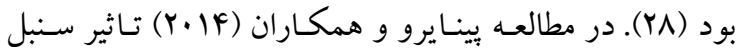

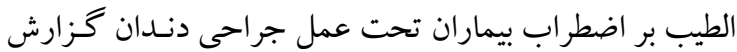

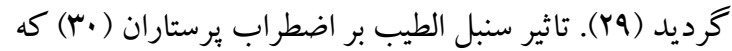

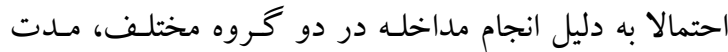
زمـان محـدود مطالعهه در مطالعه نجـف زاده و همكـاران و اختلاف نوع و شدت اضطراب گروه هاى مـورد مطالعه در هرد دو مطالعه مختلف مربوط مى باشــد و بهبود خـواب بيمـاران سرطانى (الr) كـه احتمـالا مربوط بـه ماهيـت بيمـارى، درد و

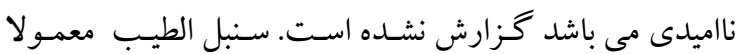
براى درمـان بس خهوابى و اضطراب استفاده مسى شـود (rr). تر كيبات دارويى حـاوى عصـاره سـنبل الطيب در تعـدادى از كشورها به علت كمبود عوارض جانبى نسبت بـه بنزوديازيين

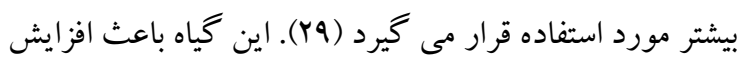

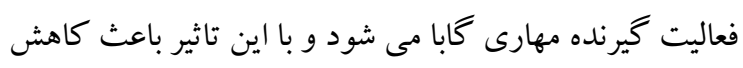

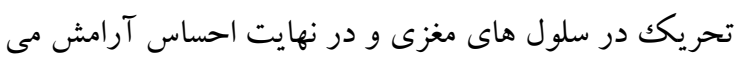

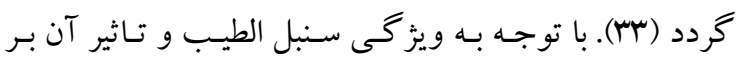

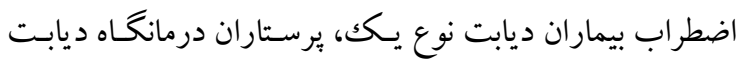

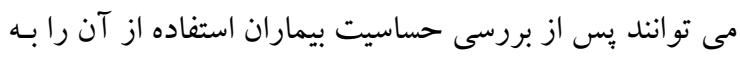
عنوان درمان مكمل توصيه نمايند.

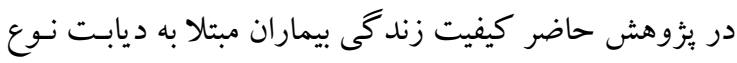

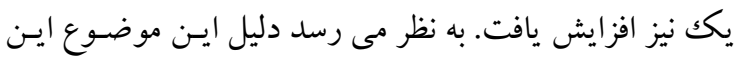


40 Sمدב فتصى

14. Fathi Ahmadsaraei N, Neshat Doost Ht, Manshaee GR, Nadi MA. The effectiveness of acceptance and commitment therapy on quality of life among patients with type 2 diabetes. I Iran J Health Educ Health Promot 2016;4:31-9. [In Persian]

15. Post MW. Definitions of quality of life: what has happened and how to move on. Top Spinal Cord Inj Rehabil. 2014;20:167-80.

16. Baghaie Lake M, Rahimi S, Adib M, Kazem Nejad Leili E, Monfared A. redictive Personal factors of quality of life in hemodialysis patient. J Holist Nurs Midwifery 2014;24:9-19

17. Mohammadi M. The quality of life of patients with diabetes from the city of Sabzevar during year 2016. Mil Caring Sci 2017;3:264-71.

18. Adriaanse MC, Drewes HW, van der Heide I, Struijs JN, Baan CA. The impact of comorbid chronic conditions on quality of life in type 2 diabetes patients. Qual Life Res 2016;25:175-82.

19. Shahinfar J, Zeraati H, Masrorniya M, Shojaei S. Comparison of valerian extract and diazepam on anxiety before orthopedic surgery. Journal of Patient Safety \& Quality Improvement 2016;4:434-40.

20. Pineau S, Legros C, Mattei C. The Medical use of Lemon Balm (Melissa officinalis) and Valerian (Valeriana officinalis) as Natural Sedatives: Insight into their Interactions with GABA Transmission. Int J Clin Pharmacol Pharmacother 2016;1:112.

21. Behboodi Moghadam Z, Kheirkhah M, Golian Tehrani S, Ghudarzi S, Haghani H, Shiroodgholami R. The impact of Valerian root extract on mood and behavioral. Med Surg Nurs J 2014;3:71-6.

22. Jannesari SH. The use of drugs in pregnancy and lactation. Advances in Nursing and Midwifery 2006;16:14-26.

23. Kazemian A, Parvin N, Raisi Dehkordi Z, Rafieian-Kopaei M. The effect of valerian on the anxiety and depression symptoms of the menopause in women referred to shahrekord medical centers. Journal of Medicinal Plants 2017;1:94-101.

24. Rafiee M, Kiani Z, Moezi SA, Rad GHM. The effects of lavender, valerian, and oxazepam on anxiety among hospitalized patients with coronary artery disease. Modern Care Journal 2018;15:e68390.

25. Khani F, Shariat S, Reza M, Mehdad A, Taki F, Kourang Beheshti M, et al. The effecti of life skills training on improving SCL-90 psychological indicators and quality of life in patients with diabetes. Knowledge \& Research in Applied Psychology 2015;15:81-91. [In Persian]

26. Nasihatkon B, Hartley R. Graph connectivity in sparse subspace clustering. Computer Vision and Pattern Recognition (CVPR), 2011 IEEE Conference. 2011 Sep.14-16, Xi'an, China.

27. Shams G, Kaviani H, Esmaili Y, Ebrahimkhani N, Manesh AA. Psychometric properties of the persian version of the padua inventory: Washington State University Revision (PI-WSUR). Iran J Psychiatry 2011;6:12-8.

28. Gharib M, Samani LN, Panah ZE, Naseri M, Bahrani N, Kiani K. The effect of valeric on anxiety severity in women undergoing hysterosalpingography. Glob J Health Sci 2015;7:358-63.

29. Pinheiro MLP, Alcântara CEP, de Moraes M, de Andrade ED. Valeriana officinalis L. for conscious sedation of patients submitted to impacted lower third molar surgery: A randomized, double-blind, placebo-controlled split-mouth study. J Pharm Bioallied Sci 2014;6:109-14.

30. Najafzadeh M, Amini K, Faghihzadeh S, Monsef esfahani H. Effect of valerian on anxiety of nurses working in the ICUs: a randomized controlled trial. PCNM 2016;5:1-12.

31. Barton DL, Atherton PJ, Bauer BA, Moore Jr DF, Mattar BI, LaVasseur BI, et al. The use of valeriana officinalis (valerian) in improving sleep in patients who are undergoing treatment for cancer: a phase III randomized, placebo-controlled, double-blind study: NCCTG Trial, N01C5. J Support Oncol 2011;9:2431.

32. Becker A, Felgentreff F, Schröder H, Meier B, Brattström A. The anxiolytic effects of a Valerian extract is based on valerenic acid. BMC Complem Altern M 2014;14:267.

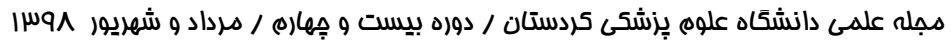


..... تاثير كيسول فوراكى

33. Bagheri-Nesami M, Gorji MAH, Rezaie S, Pouresmail Z, Cherati JY. Effect of acupressure with valerian oil $2.5 \%$ on the quality and quantity of sleep in patients with acute coronary syndrome in a cardiac intensive care unit. J Tradit Complement Med 2015;5:241-7.

34. da Costa LMF, Vieira SE. Quality of life of adolescents with type 1 diabetes. Clinics 2015;70:173-9.

35. de Ornelas Maia ACC, de Azevedo Braga A, Paes F, Machado S, Carta MG, Nardi AE, et al. Comorbidity of depression and anxiety: association with poor quality of life in type 1 and 2 diabetic patients. Clin Pract Epidemiol Ment Health 2013;9:136-41. 